\title{
Geopolítica y petróleo en el Mar Caribe: la tensión entre Colombia y Nicaragua
}

\section{Geopolitics of offshore oil exploration in the Caribbean Sea: border area between Colombia and Nicaragua}

\author{
Ginneth Pulido Gómez ${ }^{1}$ \\ Wagner Costa Ribeiro ${ }^{2}$ \\ Universidad de São Paulo, Brasil
}

http://dx.doi.org/10.15359/rgac.60-1.3

\begin{abstract}
RESUMEN
La frontera entre Colombia y Nicaragua se presenta como un escenario dinámico, caracterizado por una tensión entre ambos países, a causa de su delimitación, comprende el archipiélago de San Andrés, Providencia y Santa Catalina y el área adyacente en el mar Caribe occidental. Para resolver dicha controversia la Corte Internacional de Justicia en 2012 determinó que Colombia ejercía soberanía sobre el Archipiélago y delimitó nuevas fronteras en el mar, lo que modificó las áreas de usufructo de ambos países. Esta área se coloca en el panorama geopolítico global por dos motivos principales; primero su cercanía al canal de Panamá y al posible canal de Nicaragua, rutas estratégicas del comercio mundial, y segundo por el interés que ambos países demuestran en abrir concesiones de exploración/explotación de petróleo en el mar; en el marco de la crisis actual por la obtención de crudo, que se traduce en cambios del uso de las reservas de petróleo conocidas, las oscilaciones de los precios y los impactos socio-ambientales locales y globales generados por todas las etapas de aprovechamiento de este recurso. El presente artículo tiene por objeto discutir la vigencia de la exploración para la búsqueda de petróleo y su creciente interés en áreas offshore o fuera de costa, así como el análisis de las relaciones globales que se derivan.
\end{abstract}

1 Geógrafa e Ingeniera Ambiental, actualmente es estudiante de maestría del programa de Ciencia Ambiental de la Universidad de São Paulo, Brasil. Contacto: gpgomez@usp.br

2 Geógrafo y doctor en Geografía Humana, actualmente es profesor de los programas de posgrado en Geografía Humana y Ciencia Ambiental de la Universidad de São Paulo, Brasil. Contacto: wribeiro@usp.br 
Ginneth Pulido Gómez, Wagner Costa Ribeiro. Impacts resulting from lack of knowledge about the reference system in geospatial information of Costa Rica: utility of metadata

Palabras clave: Frontera, petróleo, Colombia-Nicaragua, geopolítica, Caribe.

\begin{abstract}
The border between Colombia and Nicaragua appears as a dynamic scenario characterized by a tension between the two countries due to their delimitation, comprising the archipelago of San Andrés, Providencia and Santa Catalina and the adjacent area in the western Caribbean Sea. To resolve this controversy, in 2012 the International Court of Justice determined that Colombia exercised sovereignty over the Archipelago and delimited new boundaries at sea, which modified the areas of usufruct of both countries. This region is important to the global geopolitical panorama for two main reasons. First, its proximity to the Panama Canal and to Nicaragua's future Canal, strategic routes of world trade. And second, the interest shown by two countries in opening up oil exploration concessions at sea, within the framework of the current crisis regarding crude oil production, which translates into lower oil reserves, price fluctuations, and local and global socio-environmental impacts generated by all stages of the use of this resource. The purpose of this article is to discuss the validity of oil exploration and its growing interest in offshore areas, as well as the analysis of the resulting global relationships.
\end{abstract}

Keywords: Boundary, oil, Colombia-Nicaragua, geopolitics, and Caribbean.

\title{
Introducción
}

El mundo contemporáneo se caracteriza por mantener y expandir patrones de consumo en concordancia con la consigna de lo que significa el mundo globalizado. El petróleo no queda fuera de tal panorama. Sin embargo, su uso agudo y constante ha llevado a que las fuentes conocidas se agoten paulatinamente, esto ha traído consigo subsecuentes crisis, que se han reflejado tanto en el aumento de los precios en el mercado como en la expansión de las fronteras de exploración. Cabe mencionar que la colocación de los precios en el ámbito del mercado global casi nunca depende de las voluntades de los territorios de donde el crudo ha sido extraído; a pesar de que la Organización de Países Productores de Petróleo (OPEP) nace como respuesta a la hegemonía occidental tradicional sobre el control de este recurso. La dependencia que gran parte de la sociedad contemporánea tiene del petróleo es tal, que diversos conflictos se fundamentan en los intentos de controlar las fuentes de extracción y sistemas de distribución y comercio, para garantizar la provisión y mantener los stocks que favorezcan a ciertos países, que dentro del panorama internacional se han mantenido como grandes potencias desde el siglo XX, como EUA y los países de Europa Occidental. Junto a ellos, crecen recientemente en consumo del hidrocarburo China y Canadá.

La compleja crisis del petróleo coloca en pauta diversos aspectos: los impactos en la economía global y local, la evidencia de agudos problemas 
socio-ambientales, la contundencia de reconocer su condición finita y la falta de un aparentemente sustituto tan versátil fisicoquímicamente, a pesar de que esto favorezca a las grandes corporaciones. Se reconocen, como resultados de su uso constante y creciente, fuertes impactos de índole socio-ambiental que merecen una amplia discusión, no pueden dejar de mencionarse el cambio climático, la generación de residuos tóxicos y la destrucción de ecosistemas como hechos de injerencia global que continúan incrementándose gracias a los devastadores procesos de explotación de recursos naturales, actualmente, vigentes para mantener el modo de producción capitalista.

Frente a estas crisis, el mercado sólo puede dirigirse a la solución que le cabe: buscar recursos en nuevas regiones que le permitan mantener, al menos temporalmente, las provisiones de petróleo, para evitar desestabilizar el mercado y las demandas crecientes, como la población que basa su estilo de vida en los derivados del mismo. Junto a esto se desarrollan técnicas y tecnologías que permiten que las extracciones se lleven a cabo en lugares poco explorados, como los lechos del fondo marino, cuya importancia para la exploración ha crecido ante la inminente disminución de otras fuentes y yacimientos.

Es en este panorama que la cuenca occidental del Caribe se presenta como una región de importancia para la posible explotación de hidrocarburos, puesto que además de la posibilidad de encontrarlos dadas las condiciones geomorfológicas del área, su situación geográfica es estratégica en relación a los flujos de comercio globales. Sumado a esto, y teniendo en cuenta que es un área relativamente pequeña presionada por las tensiones de los diferentes países o territorios que se encuentran en ella, el Caribe está en constante reconfiguración fronteriza, lo que incide directamente en la incursión de determinados actores (estatales y/o corporativos).

El presente artículo tiene por objeto discutir la exploración en búsqueda de petróleo desde la perspectiva geopolítica, limitado al área de disputa fronteriza marítimo territorial entre Colombia y Nicaragua. Para esto, fueron estudiados los procesos de configuración de los límites entre ambos países a partir de documentos históricos de la época de independencia de las Américas y la consolidación de ambos como Estados nacionales, así como otra bibliografía relacionada, también se estudiaron los acuerdos posteriores que pretendieron resolver las áreas de disputa por soberanía, 
Ginneth Pulido Gómez, Wagner Costa Ribeiro. Impacts resulting from lack of knowledge about the reference system in geospatial information of Costa Rica: utility of metadata

que incluyen líneas de litoral marítimo y el archipiélago de San Andrés, Providencia y Santa Catalina, así como el mar adyacente, para realizar una reconstrucción de los eventos más representativos en torno a la configuración de la región de estudio. Dado que Nicaragua a inicios de la década de 2000 entra con una demanda ante la Corte internacional de Justicia, son estudiados los documentos derivados del tal proceso bajo la perspectiva de las relaciones internacionales. Para el análisis de la geopolítica del petróleo, se recopilan datos de diversas entidades, como la BP, OPEP y la CIA, que permiten tener una mirada general del proceso de extracción, refinería, distribución y consumo, lo cual, y con el apoyo de teorías de la geografía política y de la justicia ambiental, permite entender la dinámica global y hacer el análisis en la escala local del fenómeno offshore en el Caribe.

Los resultados de la investigación se presentan dentro del artículo en dos partes principales, en la primera de ellas, se aborda la controversia entre Colombia y Nicaragua a partir de la compilación y explicación de los más relevantes procesos históricos de configuración de los límites marítimoterritoriales entre ambos. La segunda parte, comprende un análisis sobre la geopolítica global del petróleo para luego llegar a la escala regional en el Caribe occidental, teniendo en consideración fragilidades gubernamentales y el progresivo interés de entes corporativos que llegan a la región. Finalmente, se presentan las consideraciones alcanzadas por el estudio.

\section{La Controversia entre Colombia y Nicaragua y la exploración del petróleo}

La frontera entre Colombia y Nicaragua, área de este estudio de caso, corresponde a una frontera binacional, territorial y marítima que comprende el archipiélago de San Andrés, Providencia y Santa Catalina, y las áreas marítimas adyacentes cuya delimitación conlleva a diversos conflictos, dado que el mar Caribe tiene un área relativamente pequeña si se le compara con el número de fronteras nacionales que se trazan sobre él, que incluyen países de América del Sur, América Central y las Antillas, así como territorios, donde Estados Unidos, Francia y los Países Bajos ejercen soberanía. Esta razón hace que sea un escenario de diversos tratados internacionales, de áreas de tensión fronteriza y de algunas áreas de administración conjunta. Concomitantemente, el canal de Panamá y el posible canal de Nicaragua, que al establecerse como importantes vías del 
comercio internacional marítimo, ubicadas en la zona, imprimen al área un amplio interés geopolítico.

La llegada de empresas trasnacionales que pretenden hacer extracción, uso y aprovechamiento de diferentes recursos del mar, interfiere no sólo en los Estados involucrados en la disputa, sino que lo hace también con las dinámicas locales de todos los vecinos. Con la pretensión de abrir concesiones para exploración de petróleo, Colombia y Nicaragua involucran a la región entera y atraen el interés de otros países y empresas que tengan $u$ ofrezcan infraestructura de explotación y refinería, de esta forma se reconfigura el territorio en función de las características de la economía contemporánea, donde se presentan confluencias de índole social, ambiental y política, reflejadas en flujos de capital, bienes, servicios, recursos naturales y seres humanos, así como en la distribución desigual de ganancias y consecuencias derivadas del aprovechamiento de petróleo.

En relación a las contradicciones sobre los ejercicios soberanos en áreas en las que se entrecruzan intereses económicos es importante considerar, que en el mundo globalizado contemporáneo puede distorsionarse la percepción de la escala local, y no porque no existan informaciones suficientes sobre esta, sino más bien por la generalización de varios fenómenos que se naturalizan en el ámbito cotidiano. Del mismo modo, las dinámicas de vida singular de las sociedades contemporáneas parecen ya no pertenecer a una realidad particular, y aun perteneciendo no existe una clara noción sobre la relación existente entre estas y voluntades mayores, haciendo que el ejercicio ciudadano se encuentre supeditado a los deseos o conveniencias de entes de poder superiores a los sujetos y a veces, al propio Estado. Esto se refleja en procesos inherentes a la manutención del modo de vida actual, como la apropiación de recursos naturales y humanos para sostener dinámicas que son propias del modo de producción capitalista y que, además, han sobrepasado fronteras, es decir, es común observar entidades internacionales, transnacionales o globales, operando en diversos lugares del mundo. Y cabe suponer que existen acuerdos o contratos suscritos entre dichas entidades y los gobiernos locales, cuyos términos obligarían a un intercambio coherente entre las partes. El petróleo -y todas las actividades que se derivan de su extracción y aprovechamiento- se enmarca dentro de esta lógica. 
Ginneth Pulido Gómez, Wagner Costa Ribeiro. Impacts resulting from lack of knowledge about the reference system in geospatial information of Costa Rica: utility of metadata

Es importante comenzar por entender el proceso coyuntural que remarca la frontera entre los países de interés. Teniendo en cuenta que frontera es una línea imaginaria trazada entre dos territorios, política y administrativamente constituidos, en este caso autónomos, cuyo trazado obedece a diversos procesos, principalmente de índole económico y político. Colombia y Nicaragua son Estados nacidos de procesos poscoloniales, y como muchos otros de origen semejante, han presentado dilemas en cuanto a la delimitación de sus fronteras, la mayoría de las veces las líneas de separación entre unos y otros obedecen a las mismas demarcaciones coloniales, lo que no significa que permanezcan estáticas. Las fronteras van cambiando a partir de variados procesos, como conflictos militares, o intereses de separación locales o incluso intervenciones por parte de otros Estados.

El archipiélago de San Andrés, situado en el mar Caribe colombiano, fue objeto de disputa por parte de Nicaragua, que por varias décadas ha considerado que pertenece a su plataforma continental. Existen, por tanto, varios elementos colocados en la dinámica fronteriza entre Colombia y Nicaragua. A continuación, se elabora un recuento del proceso de delimitación de la frontera marítima y territorial.

\section{Constitución de la Frontera Marítimo-Territorial}

El Archipiélago aparece mencionado en la Real Orden del 20 de noviembre de 1803, firmada por el Virrey Joseph Antonio Caballero, en el documento se estipula que tanto el Archipiélago como la costa de Mosquitos - Lo que en la actualidad corresponde a toda la costa Caribe de Nicaragua- quedarían separadas de la Capitanía de Guatemala para ser administrados por el Virreinato de Santa Fé. El área insular era intencionalmente preservada para prevenir ataques británicos en el Caribe (Caballero, 1803)

A comienzos del Siglo XIX, como resultado de diversos movimientos independentistas, las colonias en América definían también los trazados fronterizos, para ello las nacientes repúblicas se basaban en el principio del derecho internacional de Uti Possidetis Juris para ratificar la coincidencia de los límites territoriales y las delimitaciones coloniales. En la constitución de Cúcuta, firmada el 30 de agosto de 1821, se ratificó la configuración de la Gran Colombia, en la cual implícitamente se asegura la soberanía sobre las islas. A pesar de esto, las repúblicas de América 
Central, discordaron, afianzando su presencia en la costa de Mosquitos y manifestándose contra la Gran Colombia por su presencia en el Archipiélago (Constitución de Cúcuta, 1821)

Mapa 3. Delimitación entre Colombia y Nicaragua según el tratado de 1928

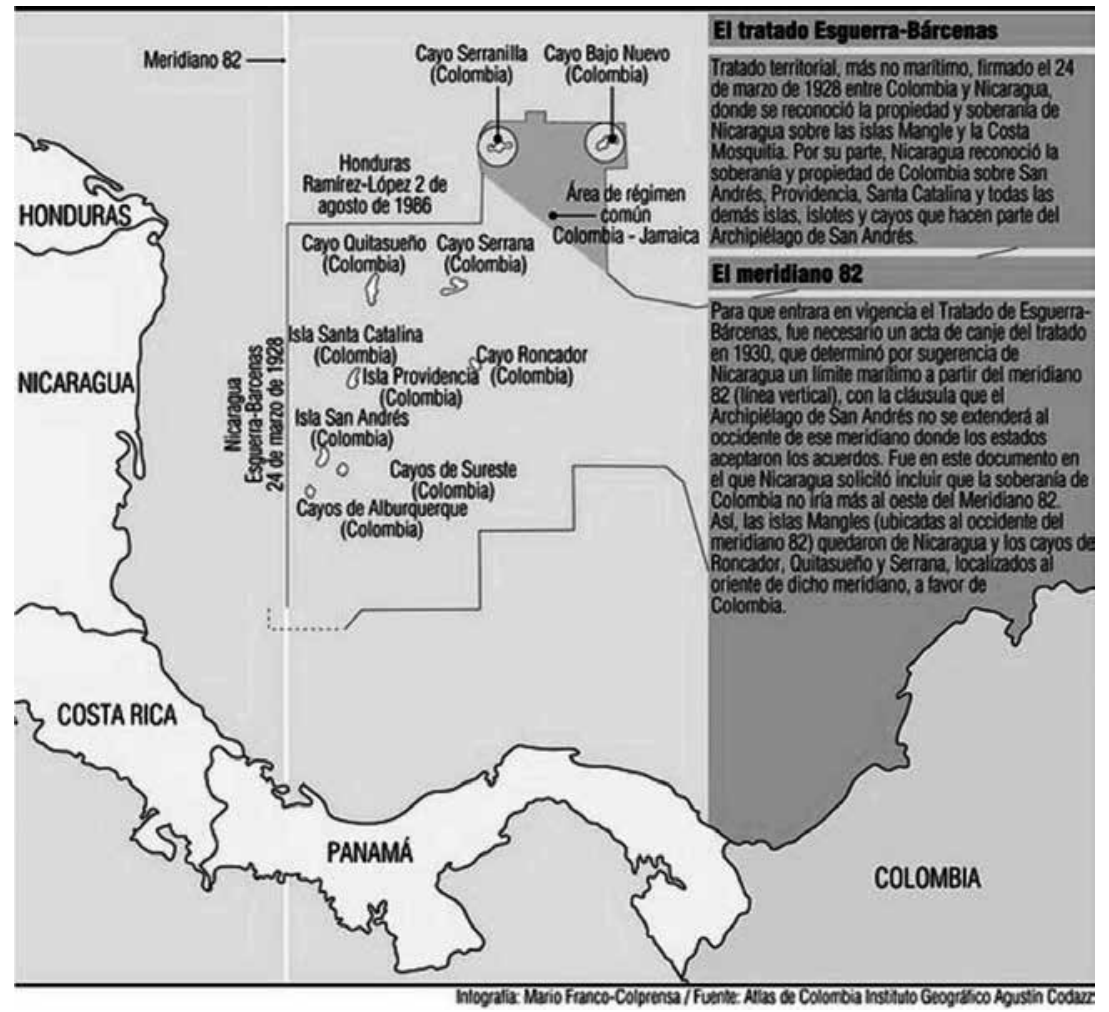

Disponible en: http:/www.eluniversal.com.co/cartagena/nacional/colombia-defendera-su-soberania-pesar-del-fallo-de-la-cij-99008, 21 de noviembre de 2012. Recuperado en septiembre de 2013.

Como consecuencia de la disolución de las Repúblicas Unidas de América Central se conformaron otros Estados, entre ellos la República de Nicaragua (1838), lo que permitió que se firmara un acuerdo con Colombia en relación a la costa de Mosquitos y al Archipiélago, dado que ya se presentaba una tensión en relación a la soberanía sobre el área y las islas. La tensión limítrofe en la región fue aparentemente resuelta en 1928, cuando los países firmaron un acuerdo que delimitaba las áreas marítima, costera e insular para cada uno. Posteriormente, el acto fue ratificado en Managua 
Ginneth Pulido Gómez, Wagner Costa Ribeiro. Impacts resulting from lack of knowledge about the reference system in geospatial information of Costa Rica: utility of metadata

el 5 de mayo de 1930 (Ver mapa 3). El tratado llamado Bárcenas-Esguerra, reconoce la soberanía y dominio de Colombia sobre las islas del archipiélago, así como la soberanía sobre la costa de Mosquitos para Nicaragua. En el acta de ratificación se especifica que el límite del archipiélago es el meridiano $82^{\circ} \mathrm{W}$, lo que significa que al occidente de dicha línea ninguna isla pertenecerá a Colombia. Esto fue interpretado por este país como el límite marítimo en el Caribe y dio inicio a la controversia manifestada por Nicaragua desde 1980 (Bárcenas Menezes \& Esguerra, 1928) (Esguerra \& Irias, 1930).

Posteriormente, EUA y Colombia firmaron el acuerdo Vásquez-Saccio en 1972 que concede la soberanía de los cayos Roncador, Quitasueño y Serrana, considerados parte del archipiélago, a Colombia, aunque los equipos de navegación construidos en ellos y los derechos de pesca de áreas adyacentes continuarían en manos de EUA hasta 1981, cuando este país renunció a cualquier pretensión sobre los cayos mencionados. Un año antes Nicaragua había manifestado ya su inconformidad y desacuerdo frente a lo estipulado en el acuerdo de 1928, afirmando que en la época se encontraba bajo control de los EUA y por tanto, no era una nación con la autonomía necesaria para suscribir cualquier tipo de tratado internacional que involucrase fronteras (Vázquez \& Saccio, 1972) (Araiza, 2014).

Por esta razón en 2001 el país centroamericano presentó ante la CIJ una petición para aclarar asuntos relativos a la soberanía del archipiélago, reclamando todas las islas, cayos y bancos -inclusive los definidos en el acuerdo con EUA- así como el área marítima en torno, con base en la Convención de las Naciones Unidas sobre el Derecho del Mar-CONVEMAR. El propósito era pedir el establecimiento de la frontera marítima y territorial que considerase las islas como parte de la plataforma marina nicaragüense, y una modificación en la ZEE, que no debería corresponder a la interpretación colombiana del acuerdo, según la cual los límites marítimos se extendían hasta el meridiano $82^{\circ} \mathrm{W}$ (mapa 3 ). A su vez Colombia pretendía que la demanda no tuviese implicaciones dado que consideraba el Tratado y la Ratificación, documentos vigentes en el marco de las Relaciones Internacionales de ambos países, argumentando además, en los documentos entregados al proceso, la falta de jurisdicción de la CIJ en una controversia resuelta bilateralmente en 1928, antes de la creación del Pacto de Bogotá (1948), por lo que no era posible aplicar lo estipulado en 
el artículo XXXI del capítulo $4^{3}$ de dicho documento. Como consecuencia la CIJ debería declarar la controversia terminada como se estipula en el artículo XXXIV ${ }^{4}$ (OEA, 1948) (International Court of Justice, 2012).

Como ya fue mencionado, el área de controversia se encuentra en una zona estratégica localizada en el mar Caribe, sobre la cual recaen intereses crecientes por parte de empresas petroleras. Cabe suponer que exista una tensión supranacional sobre la zona que involucra el proceso, puesto que aparecen también en el panorama, tensiones en relación a la definición sobre a cuál de los dos países correspondería la posibilidad de aumentar las divisas a partir de la exportación de petróleo, en caso de que sea exitosa la búsqueda del mismo. El interés por ampliar o mantener un área marítima determinada se relaciona también con la posibilidad real de usufructuar recursos provenientes del mar, en la Zona Económica Exclusiva (ZEE), ligada al archipiélago (Araiza, 2014).

Al cabo de 11 años de proceso y de documentos de parte y parte que justificaban las pretensiones estatales, la CIJ en la sentencia única e inapelable de 19 de noviembre de 2012 resuelve que la Republica de Colombia tiene soberanía sobre las islas de Albuquerque, Bajo Nuevo, Quitasueño, Roncador, Serrana y Serranilla, como parte del archipiélago de San Andrés, Providencia y Santa Catalina. Define también una delimitación marítima dividiendo la plataforma continental, con base en el marco jurídico y geográfico, a partir de lo cual se ratifica la delimitación de una nueva frontera entre Colombia y Nicaragua, además determina otra parte de la frontera marítima única alrededor de Quitasueño y Serrana. En la sentencia son indicadas con precisión las coordenadas que determinan la nueva frontera, en el mapa 4 puede verse la delimitación de esta última sentencia (Internacional Court of Justice, 2012) (Cancillería Colombia, 2016).

La sentencia reconoció el ejercicio de la soberanía política, jurídica y administrativa de Colombia en el archipiélago, que incluye islas, islotes, cayos y bancos, cuyo ejercicio soberano, según la CIJ, ha sido ejercido de forma ininterrumpida desde la colonia, durante el Virreinato de Santa Fé y hasta el momento de la sentencia. Sin embargo, realizó una delimitación sobre el mar,

3 Reconocimiento ipso facto, por parte de los Estados firmantes del Pacto de Bogotá, de la Jurisdicción de la Corte Internacional de Justicia sobre todas las Controversias de orden jurídico que surjan entre ellos. Este reconocimiento se encuentra en el Artículo 36, numeral 2 del estatuto de la Corte Internacional de Justicia.

4 Si la CIJ se declarara como incompetente para reconocer la controversia, la misma debe declararse como terminada (ibidem). 
Ginneth Pulido Gómez, Wagner Costa Ribeiro. Impacts resulting from lack of knowledge about the reference system in geospatial information of Costa Rica: utility of metadata

trazando una nueva línea de frontera en el mar, que modificó el imaginario colombiano en relación al área de usufructo en el Caribe, al determinar que $75.000 \mathrm{~km}^{2}$ son área marítima de Nicaragua, modificando la ZEE de ambos países, lo que amplía las posibilidades de abrir concesiones de exploración petrolera (Mapa 4). Como resultado de esta sentencia, el cuerpo diplomático y gubernamental de Colombia asegura haber perdido una porción del mar, en cuanto Nicaragua gana fronteras con Jamaica y Panamá, por lo que nace una nueva situación de determinación fronteriza para este país (Internacional Court of Justice, 2012) (Cancillería Colombia, 2016).

Mapa 4. Fronteras marítimas en el mar Caribe entre Colombia y Nicaragua determinadas por la CIJ en sentencia del 19 de noviembre de 2012

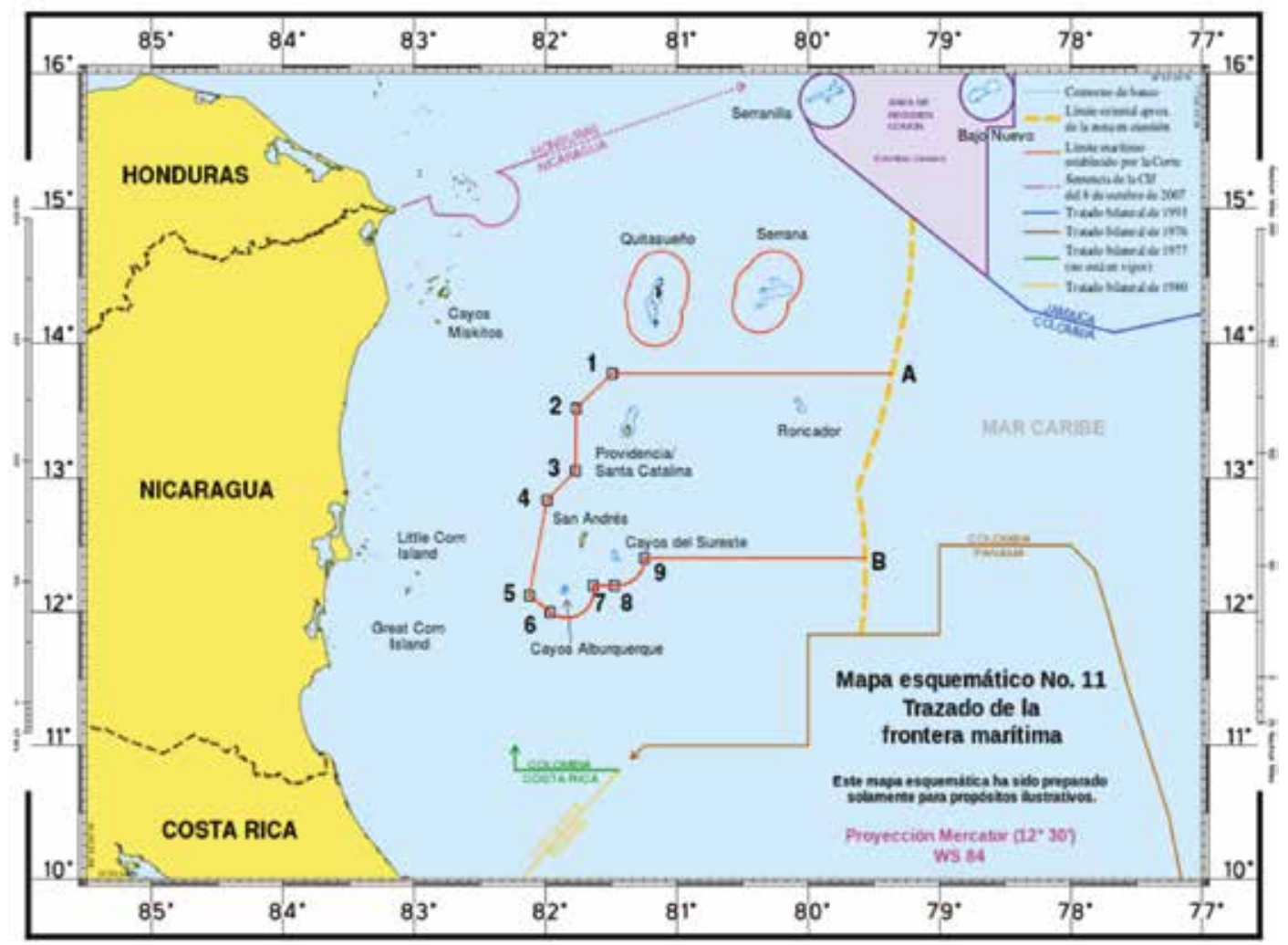

Fuente: Territorial and Maritime dispute (Nicaragua v. Colombia). Press Release Unofficial. International Court of Justice. The Hague, Netherlands, 19 November 2012. Disponible en: http://www. icj-cij.org/homepage/index.php?lang=en 
Además de la tensión por la inminente exploración de hidrocarburos, se presenta también el avance del proyecto del canal interoceánico en Nicaragua, que será construido y operado por la empresa china Hong Kong Nicaragua Development (HKND), cuyo objetivo es fortalecer el transito comercial entre Asia y varios países de América que se presentan como abastecedores de las demandas de recursos naturales de China (HKND, 2012). Sin embargo, la construcción del canal y las condiciones puestas por las partes, especialmente por China y aceptadas por Nicaragua, a la luz de las relaciones internacionales, se presentan como una intervención directa en las lógicas del Estado nicaragüense, dado que pueden vulnerarse los derechos de los habitantes de la región propuesta (a través del lago, por el río San Juan) (La Prensa, 2013) (La Voz del Sandinismo, 2013), y los impactos socio-ambientales en la zona pueden ser de graves consecuencias.

Todos los elementos identificados contribuyen a agudizar la tensión entre los países involucrados, los países subyacentes y las empresas. O sea, hay un claro interés de orden trasnacional sobre los recursos de la zona. Eso puede generar cambios en el Orden Ambiental Internacional (Ribeiro, 2010), ya que podrá alterar el flujo y posterior distribución del petróleo.

\section{Panorama geopolítico global del petróleo y offshore en el Caribe}

En la actualidad el petróleo ocupa un lugar privilegiado en el panorama energético global, a pesar de las consecuencias socio-ambientales derivadas de su uso y explotación. A continuación serán analizadas las condiciones que podrían dar origen a una posible explotación en la cuenca occidental del Mar Caribe, especialmente en la región que comprende la nueva frontera entre Colombia y Nicaragua. En primer lugar, serán relatados aspectos que explican el panorama geopolítico en torno al petróleo y los intereses de control territorial propios de su aprovechamiento, los cuales han derivado en conflictos y distribución de las relaciones de poder que modifican el Orden Mundial. Después, se presentan los intereses de exploración del petróleo en el Caribe.

El mercado global sigue exigiendo y dependiendo del petróleo como eje principal, y en caso de presentarse actividades extractivas en el área de estudio, estas determinarían cambios sustanciales en la región, junto con las modificaciones que suceden tras el fallo de la CIJ frente al litigio fronterizo y la inminente construcción del Canal de Nicaragua. Se sabe que 
Ginneth Pulido Gómez, Wagner Costa Ribeiro. Impacts resulting from lack of knowledge about the reference system in geospatial information of Costa Rica: utility of metadata

la localización de los yacimientos de petróleo alrededor del mundo es el resultado de procesos biogeográficos y geológicos particulares, que al ser descubiertos se convierten en zonas estratégicas sobre las cuales recaen los ojos de varios actores. Pero la distribución del consumo de crudo y sus derivados, así como la concentración de los lucros obtenidos a partir de este proceso de mercantilización, obedecen a otros fenómenos.

Posteriormente, y de cara a sucesivas crisis del capital, que afectaron distintos sectores inclusive el petrolero, las miradas de las empresas, de la industria y de los Estados, se volcaron sobre el mar. El hallazgo de petróleo costa afuera condujo a pensar que el océano conformaría una nueva zona susceptible de explotación y aprovechamiento, a partir de lo cual, no han sido pocas las investigaciones y estudios alrededor de la explotación offshore, las ventajas que tiene y la esperanza de mantener vivo, por algunas décadas más, el mercado de hidrocarburos, que amenaza con llegar a su fin dadas las condiciones de explotación y uso actuales.

El Caribe es un mar donde convergen varios territorios insulares y continentales de América (y algunos territorios de ultramar europeos), se presenta como un escenario complejo en donde confluyen diversos intereses políticos. En sus aguas se trazan fronteras marítimas condicionadas por las naciones que lo circundan, estas fronteras -tanto en tierra como en el agua- son dinámicas y se han transformado a lo largo del tiempo. Para contribuir con la complejidad de la zona, se abre una nueva perspectiva frente a la exploración/explotación offshore en sus aguas. De cierto modo podría pensarse que el Caribe alberga una de las últimas fronteras de commodities en el mundo, y que dados los intereses geopolíticos de la región, sumado a las características geológicas, la exploración sobre el potencial de hidrocarburos existentes en el área, se había retrasado, de forma que se presenta un interés reciente y quizás apresurado, por parte de los gobiernos de los países de la región y de las empresas globales consolidadas en la exploración de estos recursos ${ }^{5}$ (Toro Pérez, 2015).

5 Es importante mencionar que se utilizará el término economicista "recurso" haciendo referencia a elementos propios de la naturaleza cuya extracción/aprovechamiento/explotación a gran escala supone una mercantilización del mismo (commodity en las bolsas de valores), el término "recurso" reduce a la naturaleza a una simple mercancía y deja establecida su importancia en el panorama de las transacciones comerciales, razón por la cual existe unificación de precios, sin importarse por el origen o los impactos generados de su extracción/producción. 
Siendo el petróleo un recurso del cual dependen muchas de las actividades más importantes del planeta (desde la producción de energía hasta la de insumos para la industria agroalimentaria), su extracción se convierte en un fenómeno de interés global, por tanto reconocer la distribución espacial de fuentes, yacimientos y reservas, así como su estado y las fuerzas políticas que confluyen en torno a las zonas en donde se encuentra, es esencial para la comprensión de las dinámicas del mercado contemporáneo. De allí, la importancia de evaluar las implicaciones socio-ambientales de una explotación efectiva de hidrocarburos en la región, a pesar de ser este un momento reconocido como el ocaso de la era petrolera.

$\mathrm{Al}$ hacer una reconstrucción histórica de la geopolítica petrolera global, pueden reconocerse varias regiones en el planeta en donde han confluido intereses de índole supranacional ejercidos por otros Estados, empresas globales o una conjunción de ambos; lo que redunda en controles militares intensificados, tensiones políticas, crisis humanitarias e incluso conflictos bélicos. Existen algunas características comunes a muchas de estas regiones en donde suceden los procesos de producción ${ }^{6}$ de petróleo, al fin de cuentas, las consecuencias derivadas del avance del modo de producción capitalista contemporáneo, que depende de la extracción masiva de recursos naturales en detrimento de ecosistemas y poblaciones, deja como resultado nefastas huellas socio-ambientales, especialmente en regiones tradicionalmente pobres, en donde la justica ambiental resalta por su ausencia.

\section{El petróleo en el mundo}

Para hacer el análisis local en el Caribe, hace falta encadenar las dinámicas locales a las globales, teniendo en cuenta que existen múltiples variables en torno al petróleo: de índole geográfica, ambiental, económica, política y social. Según David Harvey (2011), la compleja geografía de todo, de lo local a lo global es ignorada o se reproduce en una versión simplificada del determinismo geográfico físico, muy usual en algunos estudios economicistas. Para el autor, este tipo de abordajes son peligrosos, puesto que en vías de autosatisfacer respuestas, reviven teorías darwinianas que describen la lucha entre los Estados por la dominación geopolítica.

6 Producción de petróleo para efectos de este documento hace referencia a la extracción de yacimientos, así como otros subprocesos in situ para transformarlo en energía controlada y disponible, dado que, para que el petróleo sea de hecho utilizable, suceden un conjunto de pasos: exploración, extracción, transporte, refinería, entre otros 
Ginneth Pulido Gómez, Wagner Costa Ribeiro. Impacts resulting from lack of knowledge about the reference system in geospatial information of Costa Rica: utility of metadata

Tampoco es posible evaluar cuán dependiente es la reproducción del capitalismo sobre las formas aparentemente caóticas del desarrollo geográfico desigual (Harvey, 2011).

La explotación de petróleo, así como la de otros recursos naturales y su mercantilización, generan modificaciones espaciales derivadas de la intervención en la naturaleza. Se crean espacios de conexión que resultan de los flujos de capital y de materia prima -en este caso el crudo- y también modificaciones e intervenciones conectadas al interés particular -empresarial, estatal o mixto- de mantener el control de reservas, flujos, aprovechamientos, refinerías, entre otros. Dado que los sistemas de aprovechamiento de hidrocarburos son extensivos, y el consumo del mismo ha crecido de forma acelerada gracias a las condiciones de vida y las demandas de energía de la mayoría de la población global o de las prácticas industriales -que en últimas satisfacen hábitos de consumo de una porción de la población- la búsqueda de nuevas fuentes para extracción es constante, por esto existe un interés creciente en explorar áreas nuevas, como es el caso de mares y océanos.

Existen evidencias de que el petróleo no es renovable en el corto plazo, el agotamiento de las fuentes de extracción es perceptible. Existen varios estudios provenientes tanto de iniciativas estatales como privadas, principalmente apoyados en la teoría de Hubbert que pretenden explicar el proceso de disminución del petróleo, así como su consecuente agotamiento, que traerá consigo efectos de índole económica y socio-ambiental (Ver Gráfica 1). Esta teoría estima el momento aproximado del colapso de las fuentes de petróleo, considerando que las condiciones de uso y explotación continúen como hasta ahora. Y como las estimativas demuestran que los yacimientos están agotados, las empresas y los Estados necesitan de nuevas estrategias geopolíticas y económicas decisivas para mantener el control de las reservas que quedan alrededor del mundo. 


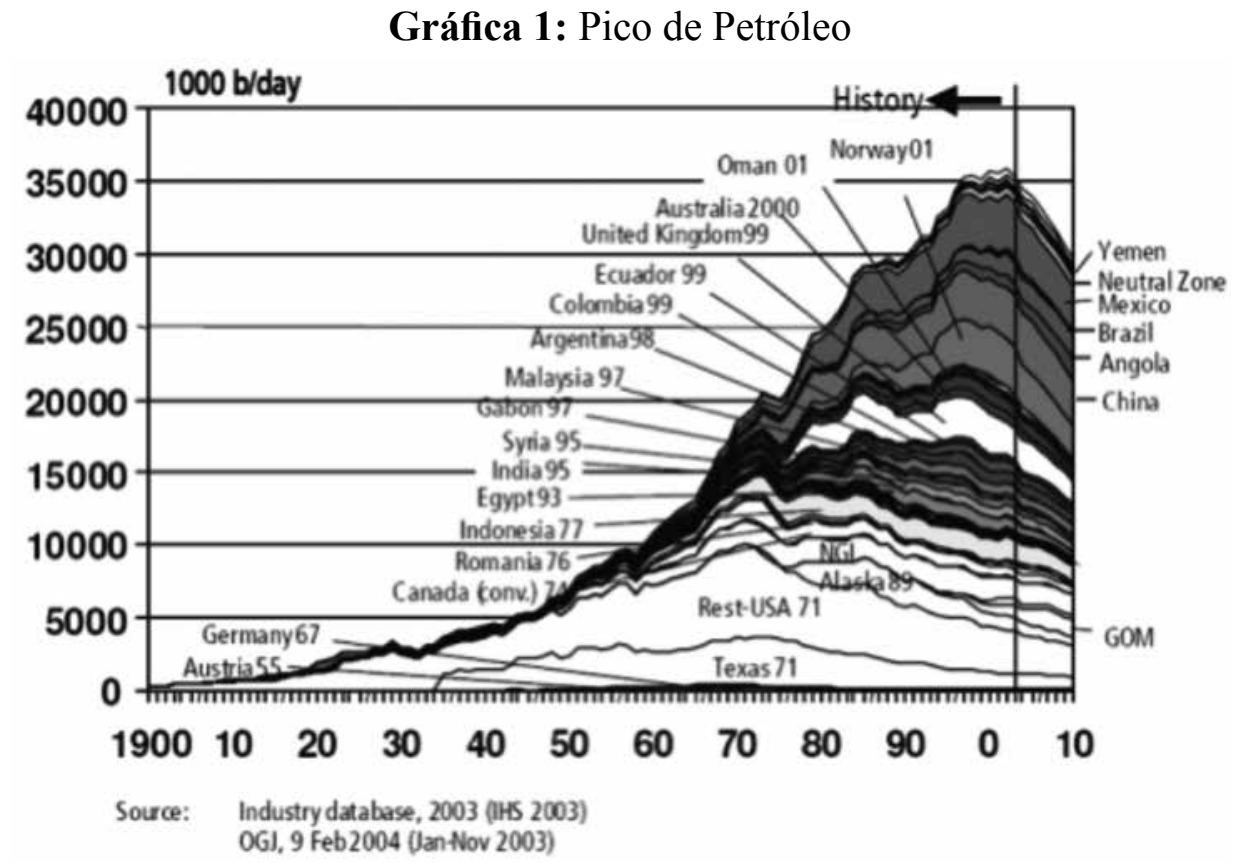

Fuente: Peak Oil (2003) Disponible en: http://peakoil.com/what-is-peak-oil

Para comprender lo que sucede en la escala regional, específicamente, en el área de la frontera entre Colombia y Nicaragua, es relevante considerar que en la zona confluyen tres particularidades que se relacionan con la búsqueda de nuevos yacimientos en el mundo: primero, la posibilidad de hacer exploración offshore en aguas profundas; segundo, el hecho de que el Caribe es una cuenca que ha sido poco explorada en la búsqueda de hidrocarburos y finalmente, la posición geoestratégica del Caribe, el cual alberga además el canal de tránsito transoceánico más importante del continente: El canal de Panamá.

A continuación, se presentan las gráficas 2 a 5 que muestran las estadísticas de reservas, producción, consumo y precios globales. Esto sirve para entender el panorama global del mercado de petróleo y pensar que existen intereses sobrepuestos de índole militar en áreas donde se concentran altas reservas del recurso. 
Ginneth Pulido Gómez, Wagner Costa Ribeiro. Impacts resulting from lack of knowledge about the reference system in geospatial information of Costa Rica: utility of metadata

Gráfica 2: Comparación de las Reservas Probadas de Petróleo por año en el mundo (en MMB por año)

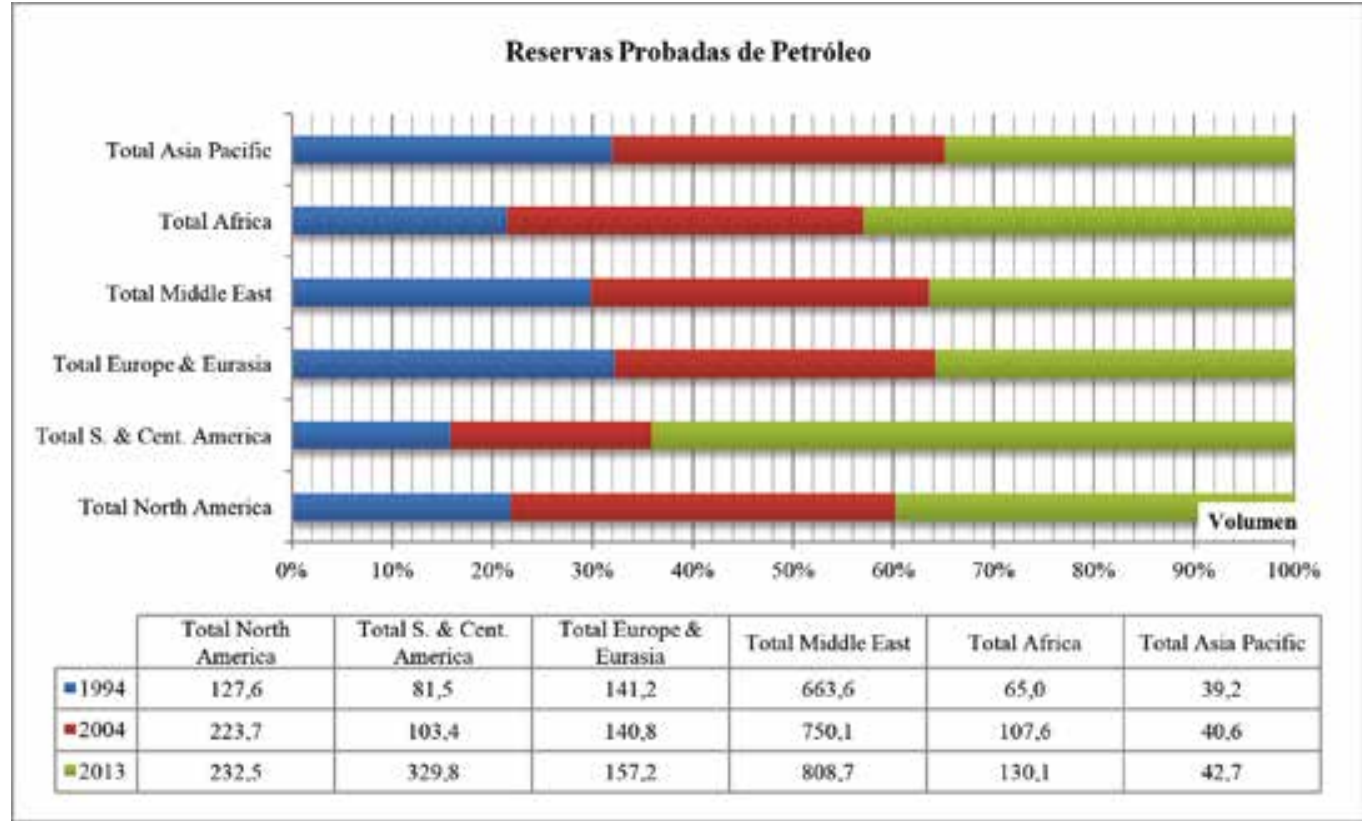

Fuente: Exploração de petróleo na Área da nova fronteira Colômbia-Nicarágua: Aproximação Geopolítica (Pulido Gómez, 2017).

Medio Oriente, por ejemplo, posee casi dos tercios de las reservas mundiales de petróleo y un tercio de las reservas de gas natural. En concordancia con lo expuesto anteriormente, Mehmet Ozkam (2011) afirma que la razón principal por la cual existe un interés permanente del mundo occidental sobre la región es esencialmente el petróleo, dado que este es explotado en su mayoría por Países de Europa Occidental, Japón y EUA. Existen procesos de rivalidad militar entre superpotencias dependientes de crudo en esta región, considerada estratégica en torno al control territorial -como sucedió durante en el caso de las guerras mundiales- suscitando la configuración de una región compuesta por países cuyo ejercicio democrático es cuestionable, al respecto, el autor asegura:

Medio Oriente es la región menos democrática del mundo. Excluyendo Turquía, Israel y, tal vez, Líbano y Palestina, ningún Estado del Medio Oriente posee un sistema democrático que siga un modelo pluralista y liberal. Excepto el Líbano y Palestina, ningún jefe de Estado árabe ha instaurado medios 
Ginneth Pulido Gómez, Wagner Costa Ribeiro. Repercusiones producto del desconocimiento del sistema de referencia en la información geoespacial de Costa Rica: utilidad de los metadatos

democráticos durante la última generación. Este carácter antidemocrático ha sido victimizado con fines estratégicos para intervenir en la región. Ya sea con el lema de llevar la democracia o por razones sistémicas necesarias para proteger el statu quo, las grandes potencias se han involucrado en los asuntos domésticos del Medio Oriente, a lo largo de la historia moderna (Ozkam, 2011, p. 108)

Gráfica 3: Producción de petróleo: Mundo de 1965 a 2014. (En millones de Toneladas por año)

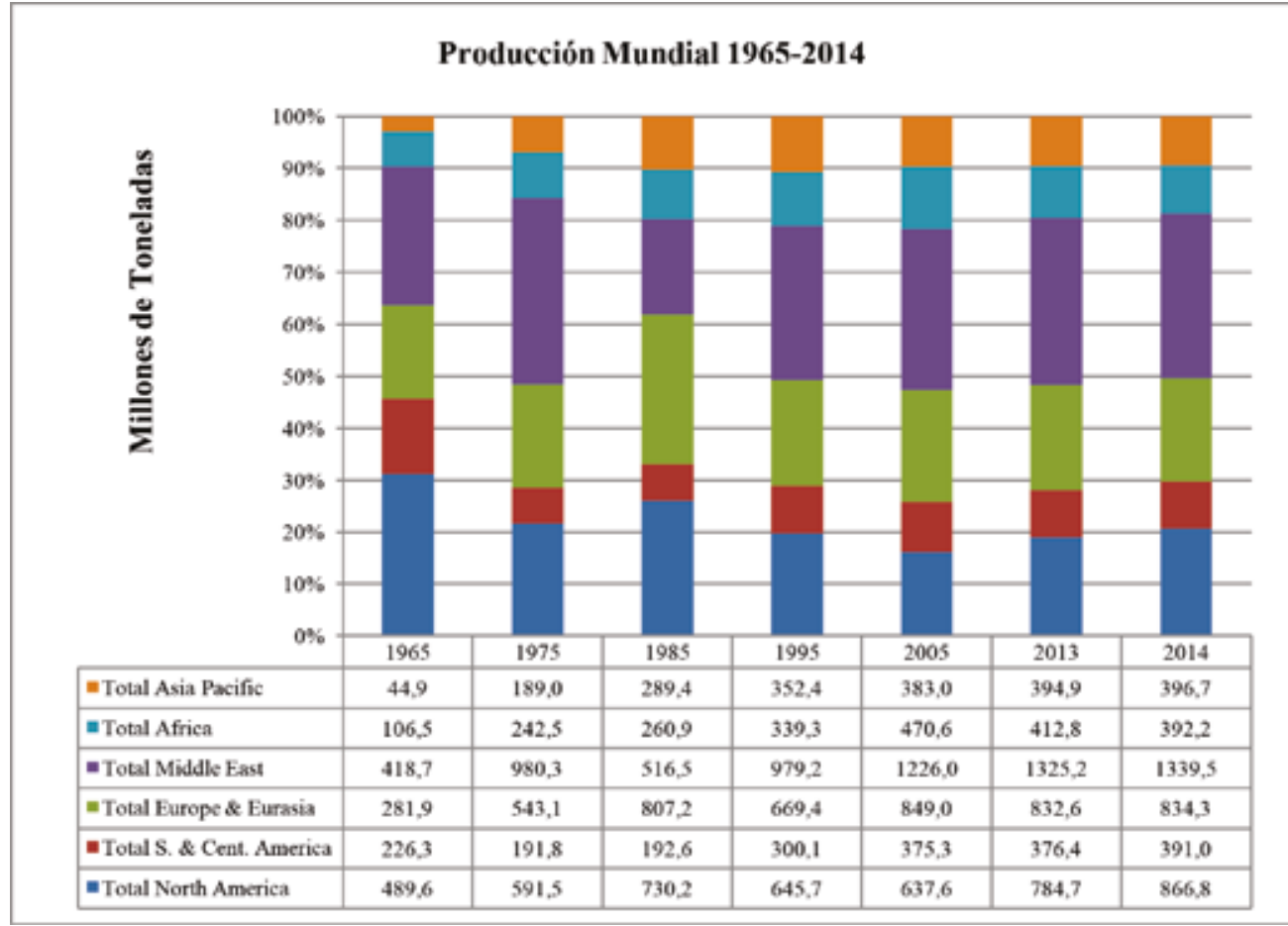

Fuente: Exploração de petróleo na Área da nova fronteira Colômbia-Nicarágua: Aproximação Geopolítica (Pulido Gómez, 2017).

La situación descrita por Ozkam define la relación asimétrica entre varios Estados, unos se especializan en proveer recursos y otros en consumirlos, espacialmente esto es mostrado en los mapas 3 y 4 , donde se muestra con más detalle las naciones que más consumen y demandan petróleo en comparación con aquellas áreas donde es producido a partir de una serie de flujos de crudo. Se verá entonces la coincidencia de esta información con la información de los países que más intervienen en pro 
Ginneth Pulido Gómez, Wagner Costa Ribeiro. Impacts resulting from lack of knowledge about the reference system in geospatial information of Costa Rica: utility of metadata

de salvaguardar las democracias (ej. EUA) sobre aquellos, cuyos sistemas democráticos han sido fragilizados (ej. Medio Oriente, Venezuela).

Gráfica 4. Consumo de petróleo regional de 1965 a 2014 (En miles de barriles diarios)

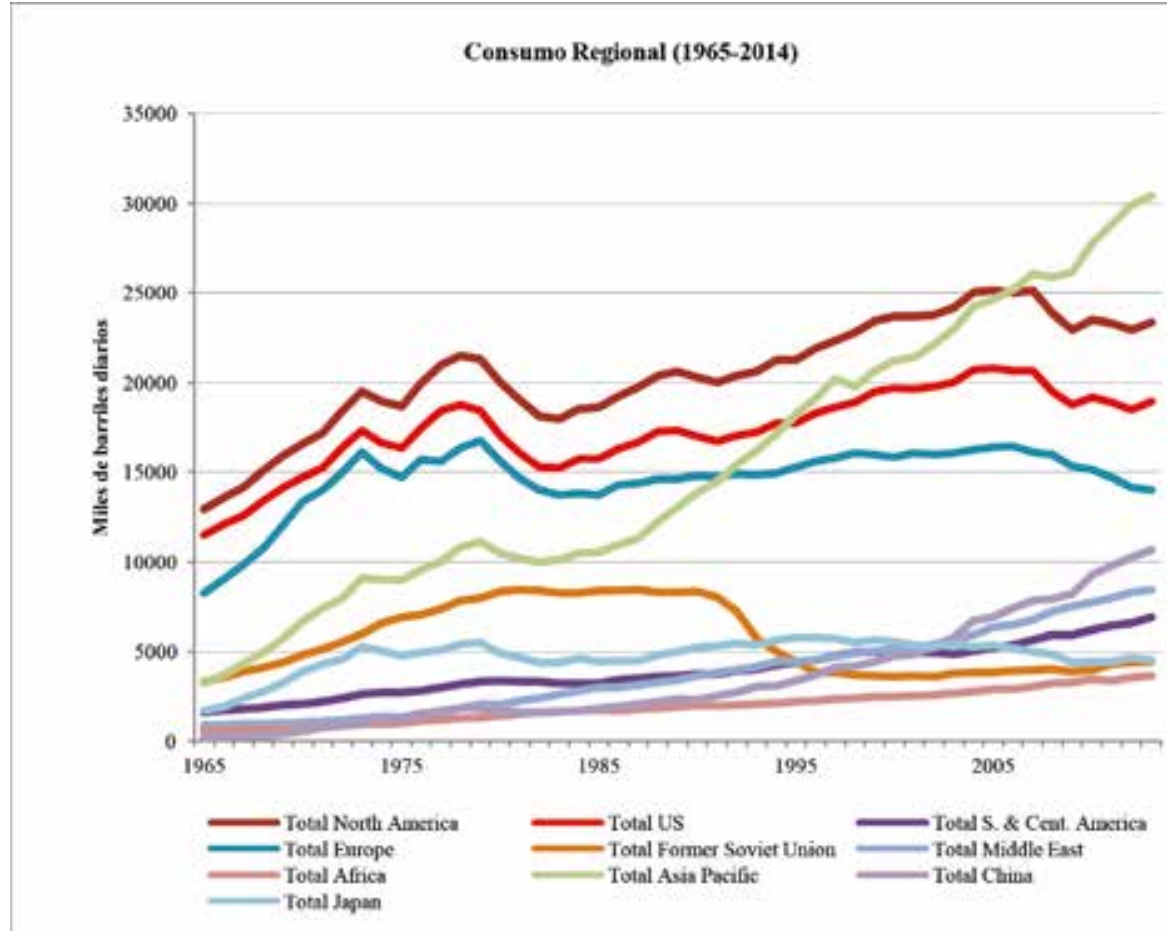

Fuente: Exploração de petróleo na Área da nova fronteira Colômbia-Nicarágua: Aproximação Geopolítica (Pulido Gómez, 2017).

Los mayores consumidores, por tanto, en función del control territorial para la obtención de crudo, se presentan como actores hegemónicos, poseedores de información estratégica que facilita la intervención constante o conveniente. Esto demuestra también la siguiente afirmación que define aspectos claves de la geopolítica petrolera: los territorios nacionales se transforman en un espacio de la economía internacional y los sistemas de ingeniería más modernos, creados en cada país, son mejor utilizados por firmas transnacionales que por la propia sociedad nacional. En tales condiciones, la noción de territorialidad es puesta en jaque e incluso puede hablarse de desterritorialización (Santos, 2014). 
Esta transformación del espacio geográfico en los territorios nacionales en función de la economía global, se da también en función del desarrollo económico desigual, cada vez más agudo, donde las diferencias entre pequeños grupos locales y arraigados a un territorio, y las corporaciones de naturaleza transnacional, carentes de lugar propiamente dicho y cuyos tentáculos se extienden a conveniencia, favorecen la idea de un "capitalismo sin fronteras", el cual es posible únicamente a partir del control y la manipulación de comunidades y ecosistemas (Santos, 2014).

Gráfica 5. Precio de petróleo regional de 1965 a 2014 (en Dólares por barril)

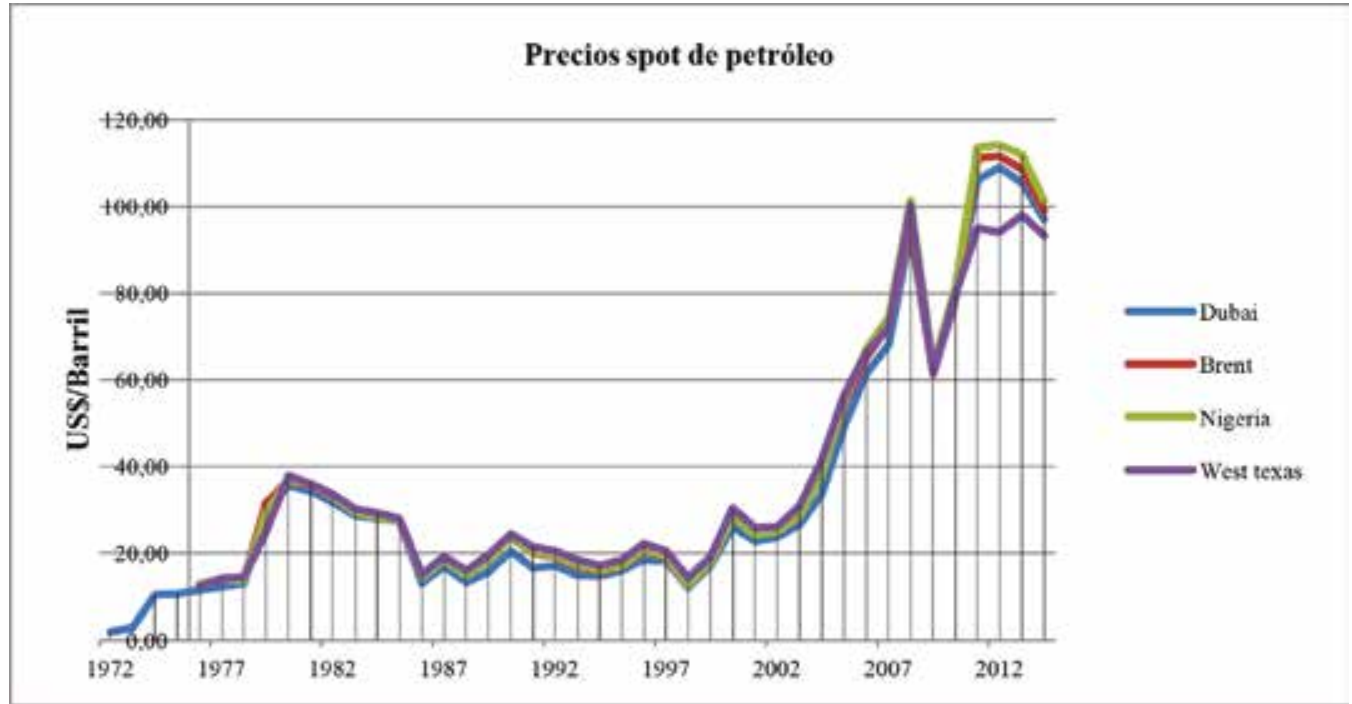

Fuente: Exploração de petróleo na Área da nova fronteira Colômbia-Nicarágua: Aproximação Geopolítica (Pulido Gómez, 2017).

Las consecuencias socio-ambientales de estas dinámicas propias del estilo de vida y consumo contemporáneo de gran parte de la población mundial, conllevan no sólo a los conflictos territoriales y militares, cargados de alta violencia y violación de derechos humanos, y los ataques sobre la soberanía ya descritos, sino que también van de la mano con el agotamiento de los sistemas naturales, la generación de residuos contaminantes - que la industria que los genera desconoce cómo tratar-, y otros fenómenos sociales como la agudización de la pobreza, el hambre y las pandemias. Todo esto enmarca los procesos de transformación de la naturaleza y la evolución humana reciente, 
Ginneth Pulido Gómez, Wagner Costa Ribeiro. Impacts resulting from lack of knowledge about the reference system in geospatial information of Costa Rica: utility of metadata

es decir, el Antropoceno, que corresponde al periodo histórico, donde se han presentado los mayores cambios en el planeta que alteran los sistemas fundamentales para el sostenimiento de la vida, debido a las actividades antrópicas, el Cambio Climático es sin duda, una expresión clara de esta era (Martínez Alier, 2014) (Chaparro Mendivelso \& Meneses Arias, 2015).

Gráfica 6: Importación y exportación de crudo y productos derivados

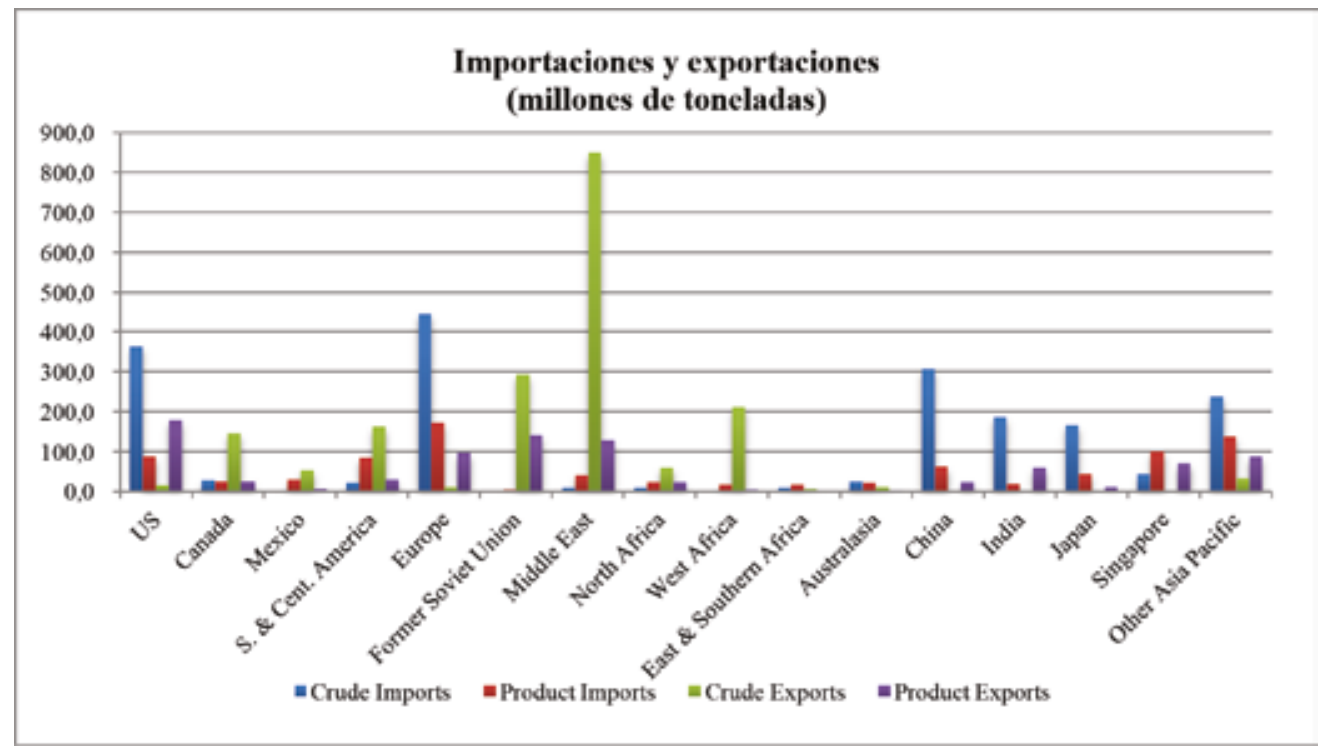

Fuente: Exploração de petróleo na Área da nova fronteira Colômbia-Nicarágua: Aproximação Geopolítica (Pulido Gómez, 2017).

Se puede concluir entonces, que para entender la geopolítica petrolera es necesario conocer como la mercantilización de este hidrocarburo ha traído consecuencias en diversos aspectos del mundo contemporáneo, impactando el sistema global, pasando por aspectos políticos, económicos, sociales, ambientales. En la gráfica 6, pueden verse las importaciones de petróleo crudo y productos de petróleo desde diferentes países/regiones del mundo, según la clasificación regional hecha por la BP en su informe anual. La cantidad de petróleo crudo que sale de Medio Oriente es visiblemente mayor en comparación a la que sale del resto de los países en la gráfica. En contraposición a esto, Europa importa la mayor cantidad de crudo, seguido de EUA y China. Las otras regiones con importantes valores en la exportación de crudo son la 
antigua Unión Soviética (entre estos sabemos que Rusia y Kazajistán reportan las mayores cantidades) el Oeste de África, Centro y Suramérica (por las exportaciones venezolanas) y Canadá.

La búsqueda intensa de nuevos yacimientos o reservas se hace urgente para evitar mayores crisis del mercado. Sin embargo, con la llegada del pico las crisis comienzan a ser definitivas, esto impacta directamente precios y procesos de explotación, puesto que el afán por atenuar los problemas derivados de la escasez llevan a la implementación de procesos más agresivos con la naturaleza, de esta forma es que las explotaciones offshore de hidrocarburos se hacen más comunes, por tanto la búsqueda de ellos en el mar, y en muchos casos no se contempla el mar como una fuente de recursos alimenticios de poblaciones costeras pequeñas, ni los ecosistemas que deben ser preservados ${ }^{7}$. Esta crisis no sólo es de petróleo, el gas, aunque con un poco más de tiempo dentro de las predicciones, está siguiéndolo muy de cerca (Marzo Carpio, 2006) (García, 2006).

Como se ha observado hasta aquí, la información presentada se relaciona a países, sin embargo, se sabe que el amplio proceso de producción, que como ya fue citado, comprende varios pasos entre los cuales están la exploración, la extracción, el transporte y la refinería, es llevado a cabo por empresas de índole privada, pública o mixta. A continuación, se relacionan las grandes empresas petroleras identificadas como las Siete Hermanas, que han mudado desde la segunda mitad del siglo XX hasta la actualidad. Estas son relevantes puesto que concentran flujos y control sobre espacios determinados, Estas informaciones pueden constatarse tanto en las gráficas 2 a 6 , como en los mapas 1 y 2 .

Dado el aumento de precio mostrado en la gráfica 6, las empresas que prevalecen como las más poderosas dentro del mercado han aumentado también su capital, agudizando de este modo la concentración del mismo. Estas se consolidan como entidades poderosas dentro del panorama del comercio internacional, a partir de su actividad extractora, las actuales empresas emergieron de las "Siete Hermanas" originales, principalmente de ExxonMobil, BP y Royal Dutch Shell, una estadounidense y dos europeas. Se considera que las compañías petroleras más poderosas, actualmente son: Saudí Aramco, Gasprom de Rusia, CNPC de China, NIOC de Irán, PDVSA de Venezuela, Petrobras de Brasil y Petronas de Malasia (Hoyos, 2007) (Jaimes, 2012).

7 Tal es el caso de la Reserva de la Biósfera Seaflower, en el área de investigación. 
Ginneth Pulido Gómez, Wagner Costa Ribeiro. Impacts resulting from lack of knowledge about the reference system in geospatial information of Costa Rica: utility of metadata

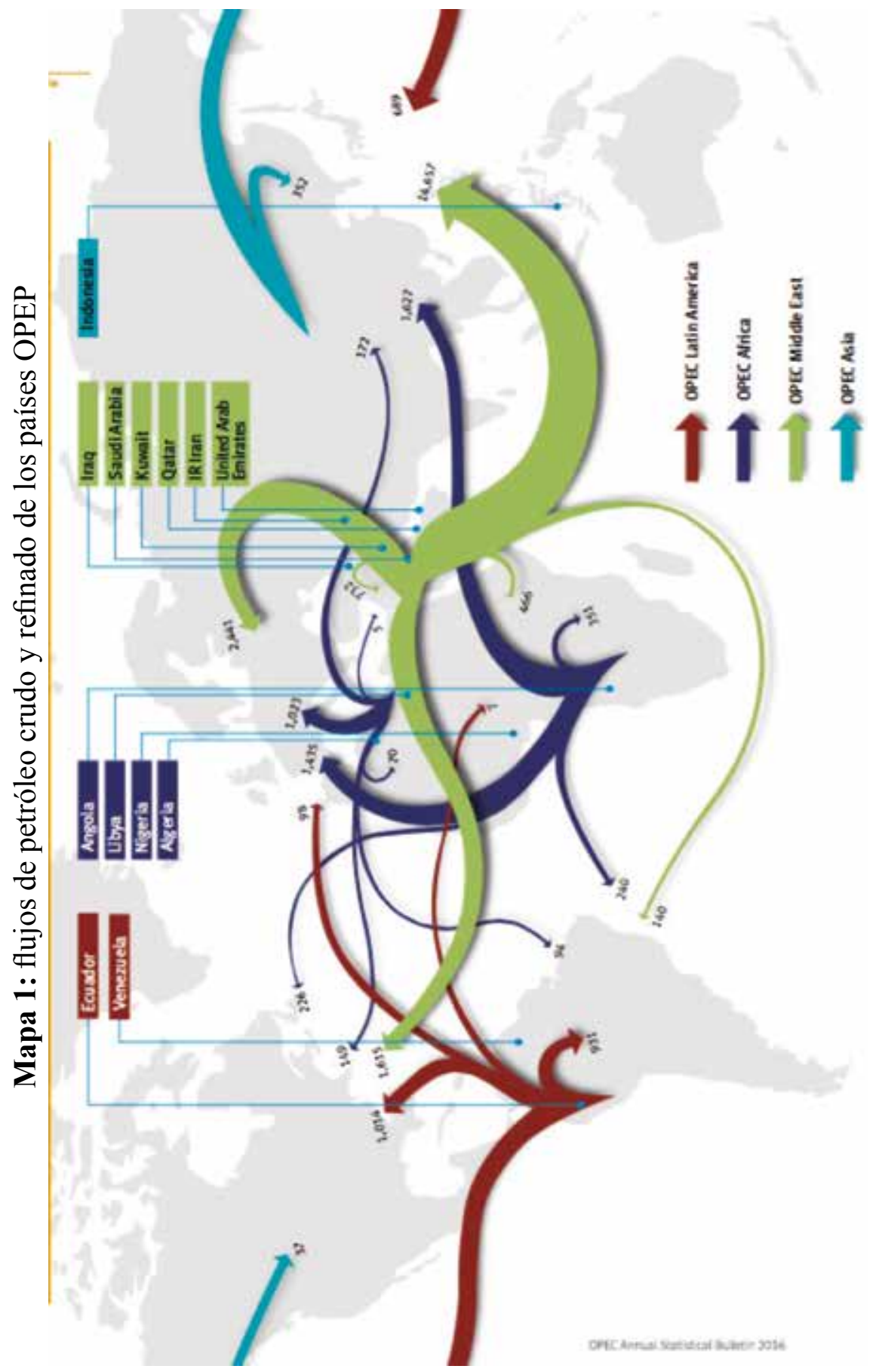

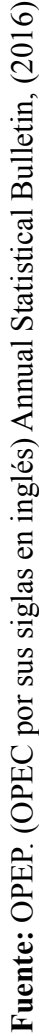


Ginneth Pulido Gómez, Wagner Costa Ribeiro. Repercusiones producto del desconocimiento del sistema de referencia en la información geoespacial de Costa Rica: utilidad de los metadatos

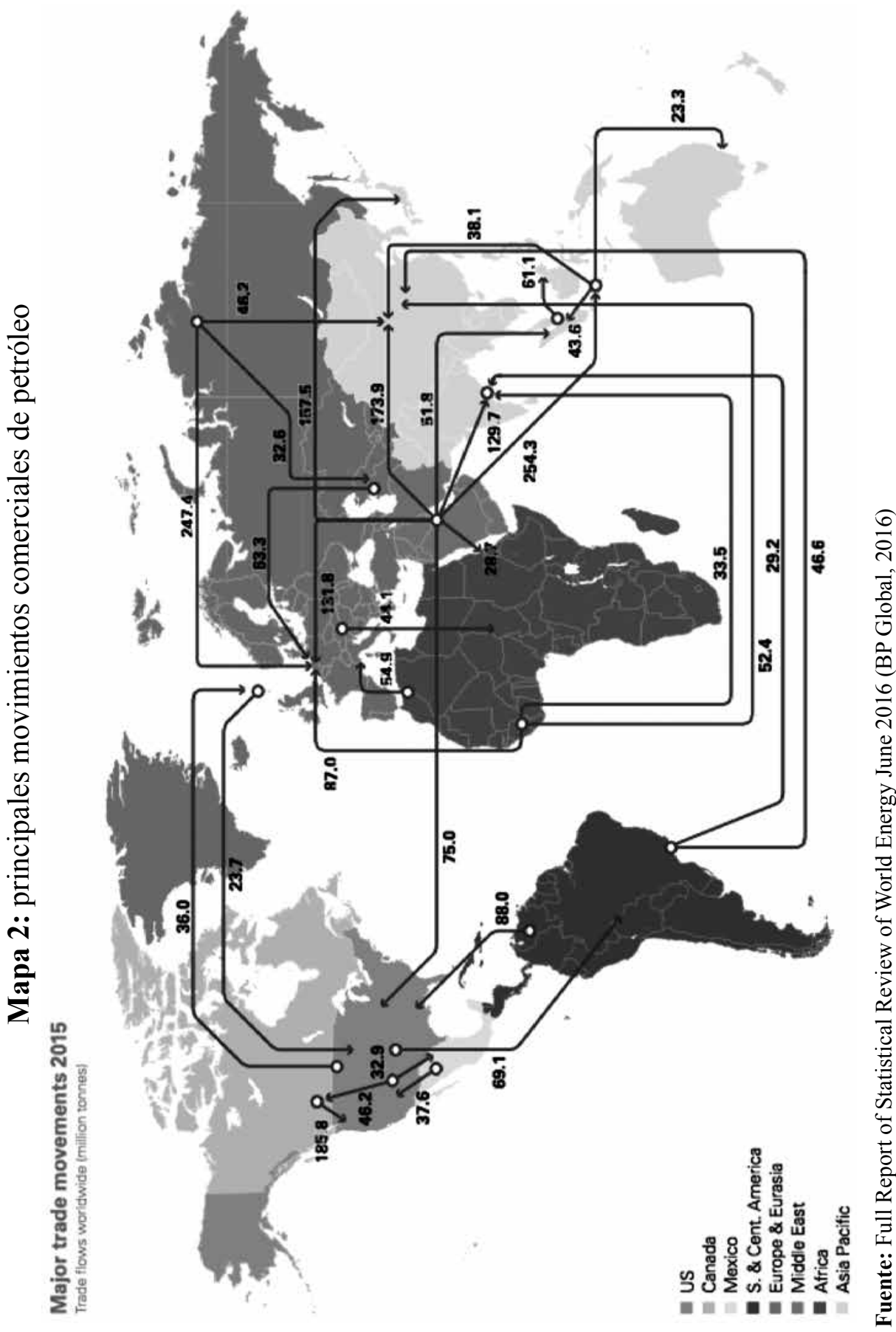


Ginneth Pulido Gómez, Wagner Costa Ribeiro. Impacts resulting from lack of knowledge about the reference system in geospatial information of Costa Rica: utility of metadata

En los mapas 1 y 2 se ilustran los flujos de petróleo global. El primero de ellos indica a través del grosor de las flechas la cantidad de flujo de petróleo que sale de países de la OPEP, se constata que las líneas más gruesas salen de Medio Oriente y de África, y se dirigen a Europa occidental, Norteamérica y Asia, con mayor incidencia. El segundo mapa enseña los flujos comerciales de petróleo sin distinción entre países OPEP, en este, además de lo encontrado en el anterior mapa, puede observarse que existen flujos representativos hacia China, provenientes principalmente de Brasil y Rusia. Llaman también la atención las cantidades de petróleo que llegan a Norteamérica, lo que ratifica a la región (y de paso a los EUA) como la que presenta mayor consumo total y per cápita (Pulido Gómez, 2017)

A comienzo de la década de 1970, varios países, inclusive Estados del Caribe, apoyaron la implementación de delimitaciones marítimas, como la definición de la ZEE, cuya delimitación es compleja en una región como el Caribe, dado su tamaño y la cantidad de Estados independientes que lo rodean, esta situación favorece el surgimiento de disputas entre vecinos, de diferentes niveles (Morris, 1986). Complica aún más la situación regional el proceso de militarización que se ha agudizado en varios países latinoamericanos, con ello, las disputas territoriales se agudizan y complican el orden regional. Las dinámicas que inciden en el orden mundial se basan entonces, en una sumatoria de políticas estatales o privadas que pretenden concentrar la extracción, aprovechamiento y flujo de recursos, con los consecuentes lucros que genera y las alianzas militares sucedidas no por casualidad de estos intentos de control. Con la llegada de empresas petroleras a la cuenca del Caribe, la construcción del canal de Nicaragua en manos de China y las tensiones políticas actuales, nuevos actores se encuentran en el área de litigio, para evitar intervención o para iniciarla, con el fin de mantener las relaciones de poder colocadas en la actualidad contemporánea.

\section{Los acuerdos de exploración}

Los acuerdos que se encuentran en vigor o en proceso al término de este documento son: El acuerdo 186 de 2006, trata de la firma de un acuerdo entre Nicaragua y la empresa Infinity Energy Resources. El 3 de abril de 2006, Nicaragua delegó al procurador general de la república para suscribir un contrato de exploración y explotación petrolera con la Empresa MKJ Exploraciones Internacionales S.A., en el acuerdo 111 de 2006, 
en la cuenca cercana a la Costa de Mosquitos, en un área de $4.000 \mathrm{Km} 2$. Mediante el acuerdo presidencial $N^{o} 16$ de 2008, se suscribe otro contrato entre la república de Nicaragua y MKJ Exploraciones Internacionales S.A. En el 2008, se aprueba el contrato de explotación de Hidrocarburos con la empresa Infinity Energy Resources, en el área conocida como banco Tyra, en lo que Nicaragua denomina Atlántico Sur. El 10 de julio de 2013, Nicaragua firma un tratado de exploración con Repsol, aprobado en una resolución de septiembre de 2012. Finalmente, Ecopetrol, de Colombia, resalta el hallazgo de petróleo en aguas profundas, en un área más cercana a La Guajira. A pesar de no existir contratos accesibles en las zonas de exploración probable, por parte de Colombia, la división de bloques de concesión es una evidencia del interés por aprovechar la situación de la crisis global y abrir las puertas al offshore.

Ambos países muestran una inclinación evidente a la exploración, se muestran favorables a la incursión a pesar de que el mundo actual denota un decrecimiento sostenible, como lo llama Joan Martínez Alier (2014), frente al descenso de las fuentes de petróleo, las consecuencias en las áreas locales, teniendo en cuenta que para el caso en partículas el área de la reserva Seaflower se vería inevitablemente afectada, puesto que no habría como protegerla en una eventual explotación. Los intereses económicos hegemónicos, y la lógica de las burguesías nacionales en ambos casos, han llevado a una carrera a favor de las concesiones que puede terminar en mayores tensiones de las que ya existen en la región. Nicaragua contribuye a agudizar estas tensiones en vistas de la construcción del canal, que la dejará en situación de desventaja en lo que tiene que ver con las ganancias y el control del territorio, a pesar de presentarse esta opción, según el presidente Ortega como una oportunidad para enfrentar el imperialismo norteamericano, a la vez que firma contratos con empresas estadounidenses, lo que conlleva a una clara contradicción.

Aunque aparentemente Colombia y Nicaragua poseen los mismos propósitos en torno a preservación y justicia, lo que se encuentra por detrás de los intereses y las negociaciones de ambos en La Haya, no va de la mano con una política clara de preservación del área protegida del archipiélago ni de los derechos sociales de sus habitantes. Puesto que se evidencia el interés por abrir posibilidades de extracción de recursos, concediendo a otros dicho beneficio. Cabe recordar que posterior a la decisión 
Ginneth Pulido Gómez, Wagner Costa Ribeiro. Impacts resulting from lack of knowledge about the reference system in geospatial information of Costa Rica: utility of metadata

del tribunal internacional, Colombia reaccionó desfavorablemente asegurando que no acataría el fallo, lo que demuestra que la tensión continua en vigencia y que la disputa por el usufructo del mar no ha sido resuelta, por ello, si las exploraciones son exitosas en el hallazgo de hidrocarburos, ciertamente el conflicto continuará vivo.

\section{Consideraciones finales}

Cabe mencionar que la tensión fronteriza aparentemente resuelta en el papel por la determinación de la CIJ, se mantiene dada la negación de Colombia y el aumento de la tensión entre ambos, puesto que no existe una evidente voluntad de negociación, además de la carrera de ambas naciones por conceder contratos de exploración. Hay que considerar en conjunto, una vez más, el desarrollo capitalista, sus impactos ambientales, sociales y su lógica distributiva desigual, la importancia que conlleva el hallazgo de fuentes de petróleo por cualquiera de los países denota una ganancia, a pesar de injusta, para el país en cuyo territorio se den los hallazgos, la tensión por el área susceptible de explotación se agudiza frente a la evidencia de petróleo. No es importante -ni siquiera es comentado en los medios- la situación de la crisis de petróleo, las crisis de precios se abordan porque no son fáciles de ocultar, toda vez que un aumento en los precios de los hidrocarburos redunda en el aumento del costo de vida, casi de manera general.

En este sentido es de interés geopolítico entender cómo es que la crisis del petróleo en el panorama global llegó a una región con un conflicto particular, las razones por las que se generan esos desplazamientos geográficos de la crisis de capital y de recursos naturales. El desarrollo geográfico desigual, producto del capitalismo, explica en parte que para la manutención del modo de producción, las crisis -o la búsqueda de soluciones a ellas- se desplacen hacia las zonas de donde pueden extraerse recursos para intentar mantener el supuesto equilibrio de la producción que no se contabiliza y que en realidad son efectos socio-ambientales crecientes, de diferentes matices, que se distribuyen de manera desigual, afectando por lo general poblaciones más vulnerables y pobres históricamente, perpetuando y agudizando dicha situación.

Como la acumulación de capital es un proceso que no existe fuera de los determinados contextos geográficos, vale recordar que áreas de tensión política son un nido perfecto para la generación de capital, a partir de la 
extracción de recursos. Es más simple alterar las configuraciones de los Estados, como asegura Harvey, para conseguir los objetivos de acumulación, se reconfiguran los espacios, las fronteras e intervienen en la determinación de los gobiernos y los pueblos de un territorio, a través de ofensivas militares -que generalmente traen consigo el discurso de la restauración de la democracia- que alteran el orden mundial vigente, nunca estático.

Para el caso de la Cuenca del Caribe, vale la pena recordar que se ha avanzado en la exploración de los océanos en la búsqueda de alimentos, combustibles y además ha sido receptor de residuos, algunos de ellos tóxicos. Los cambios ambientales en el planeta han sido contundentes y por lo pronto algunos son irreversibles, el agotamiento de muchos recursos es evidente y la búsqueda de fuentes nuevas de ellos es constante y agresiva, puesto que se consideran las urgencias que presentan las demandas de petróleo, para el caso, sobre cualquier efecto negativo resultado de su extracción, uso, combustión y disposición final.

Se evidencia, que desde antes que la Corte de Internacional de Justicia definiera los nuevos límites fronterizos, el panorama del mercado estaba puesto sobre los dos países, los intereses de la exploración en el área nacen quizás de evidencias geológicas, al menos actualmente, se trabaja en la búsqueda de condiciones que favorezcan el aprovechamiento de los hidrocarburos, lo que colocaría a Nicaragua en el panorama del petróleo global, dependiendo de lo que finalmente suceda con la frontera cuya definición aún se encuentra bajo procesos de tensión por parte de ambos países.

\section{Referencias}

Araiza, R. (2014). Conflicto Colombo-Nicaragüense desde la perspectiva de la Jurisprudencia de la Corte Internacional de La Haya. Memorias del foro internacional Fronteras en el Caribe.

Bárcenas Menezes, J. \& Esguerra, J. M. (1928). Tratado sobre cuestiones territoriales entre Colombia y Nicaragua. Recuperado el 12 de 03 de 2013, de Fundación Enrique Bolaños: http://sajurin.enriquebolanos. org/vega/docs/1928\%20TRATADO\%20SOBRE\%20CUESTIONES\%20TERRITORIALES\%20ENTRE\%20COLOMBIA\%20 Y\%20NICARAGUA.pdf

Caballero, J. A. (20 de Noviembre de 1803). Real Orden de 1803. Recuperado el 20 de Mayo de 2015, de Pasaporte Colombiano: 
Ginneth Pulido Gómez, Wagner Costa Ribeiro. Impacts resulting from lack of knowledge about the reference system in geospatial information of Costa Rica: utility of metadata

https://pasaportecolombiano.wordpress.com/2007/12/16/ documento-real-orden-de-1803/

Cancillería Colombia. (2016). Controversia Territorial y Marítima (Nicaragua c. Colombia) 2001-2012. Recuperado el 25 Febrero de 2016, de http://www.cancilleria.gov.co/casos_corte/nicaragua_colombia

Carpio, M. (Marzo-Junio, 2006). El hombre del hidrocarburo y el ocaso de la era del petróleo. Mientras Tanto, 98, 105-121.

Chaparro Mendivelso, J. \& Meneses Arias, I. (Diciembre de 2015). El Antropoceno: Aportes para la comprensión del Cambio Global. (U. d. Barcelona, Ed.) Aracne - Geocrítica(203).

Constitución de Cúcuta. (06 de Octubre de 1821). Recuperado el 13 de Mayo de 2015, de https://es.wikisource.org/wiki/ Constituci\%C3\%B3n_de_C\%C3\%BAcuta

Corte Internacional de Justicia. (10 de Marzo de 2015). Estatuto da Corte Internacional de Justiça. Obtenido de http://www.icj-cij.org/homepage/sp/icjstatute.php

Esguerra, M., \& Irias, J. (05 de Mayo de 1930). Pasaporte Colombiano. Obtenido de Acta de canje de Ratificaciones, Protocolo de 1930: https://pasaportecolombiano.wordpress.com/2007/12/13/ documento-protocolo-de-1930/

García, E. (Marzo-Junio de 2006). Del Pico del petróleo a las visiones de una sociedad pos-fosilista. Mientras tanto, 98, 25-47.

Harvey, D. (2011). O enigma do Capital: as crises do capitalismo (Primeira Edição ed.). (B. Tempo, Ed., \& P. JOÃO ALEXANDRE, Trad.) São Paulo, Brasil.

HKND. (2012). HKND Group: Hong Kong Nicaragua Canal Development. Obtenido de http://hknd-group.com

Hoyos, C. (17 de Marzo de 2007). The New Seven Sisters: oil and gas giants and western rivals. Recuperado el 22 de Abril de 2016, de http:// www.ft.com/content/471ae1b8d002-22db-94cb-000b5df10621

Internacional Court of Justice. (19 de November de 2012). Territorial an Maritime dispute (Nicaragua v. Colombia). Recuperado el 28 de Marzo de 2013, de Press Release Unofficial: http://www.icj-cij.org/ homepage/index.php?lang=en

International Court of Justice. (19 de 11 de 2012). Reports of Judgments, Advisory, Opinions and Orders. Territorial and Maritime Dispute 
(Nicaragua v. Colombia). Recuperado el 2013, de http://www.icjcij.org/docket/files/124/17164.pdf

Jaimes, M. (Julio-Diciembre de 2012). Petróleo: Historia y perspectivas geopoliticas. Aldea Mundo, 17, 65-70.

La Prensa. (13 de Junio de 2013). Orteguismo aprueba construcción del Canal. Recuperado el 28 de Noviembre de 2015, de Diario de los Nicaragüenses: http://www.laprensa.com.ni/2013/06/13/ politica/150676-orteguismo-aprueba-construccion-del-canal

La Voz del Sandinismo. (2013). Gran Canal Interoceánico de Nicaragua. Recuperado el 12 de Mayo de 2015, de http://www.lavozdelsandinismo.com/gran-canal-interoceanico-de-nicaragua/

Martínez Alier, J. (2014). O Ecologismo dos pobres. (M. WALDMAN, Trad.) São Paulo: Editora Contexto.

Morris, M. (Enero de 1986). Maritim Geopolitics in Latin América. Political Geography Quarterly, 1, 43-55.

OEA. (Abril de 1948). Pacto de Bogotá. Recuperado el 15 de Noviembre de 2015, de Organización de los Estados Americanos: http://www. oas.org/juridico/spanish/tratados/a-42.html

Ozkam, M. (Enero-Junio de 2011). El Oriente Medio en la politica mundial: Un enfoque sistémico. Estudios Políticos, 99-120.

Pulido Gómez, G. (2017). Exploração de petróleo na área da nova fronteira Colombia-Nicaragua: Aproximação Geopolítica. (I. d. Ambiente, Ed.) São Paulo, Brasil: Universidade de São Paulo.

Ribeiro, W. C. (2010). Geografia política e a questão internacional dos recursos naturais. Estudos Avançados, 69-80.

Santos, M. (2014). A Natureza do Espaço (4a Edição, 8a reimpressão ed.). São Paulo: Edusp.

Toro Pérez, C. (10 de Septiembre de 2015). La geopolítica del extractivismo marino en el Caribe Occidental. Grupo Semillas, 59.

Vázquez, A., \& Saccio, L. (18 de 09 de 1972). CANCILLERÍA COLOM$B I A$. Recuperado el 2013, de Tratado entre el Gobierno de la República de Colombia y el Gobierno de los Estados Unidos de América Relativo a la situación de Quitasueño, Roncador y Serrana.: http:// www.cancilleria.gov.co/colombia/sovereignty/affairs 